\title{
Trends in Economic Independence of Young Adults in the United States: 1973-2007
}

\section{Introduction}

The transition to adulthood since the late 1970s has become increasingly complicated and prolonged compared to the very swift passage that occurred in the post-World War II era. ${ }^{1}$ Typically, the demographic package of adult transitions has included such markers as leaving home, finishing education, securing a job, and marrying or cohabiting, and having children (Settersten, Furstenberg and Rumbaut 2006). In the post-war years, the transition occurred quickly (usually by age 25 for both men and women) and in an orderly sequence beginning with school completion, full-time work, and home-leaving. Since then, the transition has lengthened and become more circuitous.

Public and scientific discussion over why the transition to adulthood changed so suddenly has not yet reached any consensus on this question. Clarifying this question involves, we contend, understanding when and how economic self-sufficiency is attained. There has been considerable speculation that shifts in the labor market require more education and training to become economically secure enough to establish a family (Berlin, Furstenberg and Waters 2010). Moreover, the structure of the U.S. labor market itself has been reformed significantly in the last 30-40 year in the face of global competitive pressure. Increase in earnings inequality, in employment instability, and shortening of job tenure due to higher turnover are some of the most relevant changes that occurred since 1970s. Together with these structural changes, youths' expectations about what it takes to live independently have risen, along with the actual costs of living.

This paper explores the trends in the achievement of economic self-sufficiency over time by comparing the life course of young adults in 1973, 1987 and in 2007, using data from the National Longitudinal Surveys in 1966 (NLS Original Cohorts), in 1979 (NLSY79) and 1997 (NLSY97). These three data sets enable us to compare individuals between ages 22 and 30 in

\footnotetext{
${ }^{1}$ Even though the delay in the transition is less pronounced in the United States than in some countries in Europe such as Italy, Spain and Portugal, where today young adults leave home in their late 20s, between 5 and 7 years later than those leaving home in the 1960s and 1970s (Billari, Francesco C., and Chris Wilson. 2001. Iacovou, Maria. 2001.) - over the last three decades, Americans have experienced large changes in rates of household formation and dissolution. Age at leaving parental home, age at marriage and rates of non-marriage, extra-marital childbearing and divorce have all risen (Aassve, Arnstein, Simon Burgess, Andrew Chesher, and Carol Propper. 2002. Billari, Francesco C., and Chris Wilson. 2001.).
} 
1973, 1987 and 2007, while accounting for the role of educational attainment and family background. Our research builds on a line of previous research suggesting that it takes longer today to build the human capital necessary to establish economic independence and as a consequence, a growing number of young adults may linger for a long time in a state of semiautonomy.

The next section presents a review of the past works on labor market outcomes and economic self-sufficiency, trying to reflect about the causes of its postponement. After describing the specific contributions of our study we present our samples and the methodological strategy for the empirical analysis. Sections 4 and 5 report our findings, and section 6 concludes.

\section{Background}

Previous research has demonstrated that the transition to adulthood since the late 1970s has become increasingly complicated (Aassve et al. 2002; Furstenberg 2010; Settersten, Furstenberg and Rumbaut 2006). Financial independence is a fundamental step to be considered an adult, associated with - but not identical to - full-time employment. As noted by Yelowitz (Yelowitz 2005) in an article discussing the widely-held perception that the transition to adulthood has become longer, many young people (aged 19-28) in the US do not consider themselves "financially independent enough" to be an adult. The achievement of economic self-sufficiency, however, has been delayed together with the other events leading to adulthood, possibly due to reduced economic opportunities and to the stagnation of real wages for many groups of American workers during the 1970s and 1980s (Duncan, Boisjoly and Smeeding 1996; Katz and Autor 1999). Changes in the labor market over the past forty years, e.g. technological changes in the production process, spread of globalization, the decline of unionization, etc. made it more difficult for young adults to attain economic stability and self-sufficiency (Danziger and Ratner 2010; Duncan, Boisjoly and Smeeding 1996).

There is, therefore, good reason to believe that it takes longer today to achieve a wage that permits economic autonomy and, in particular, enough to establish a separate household and support a family (Danziger and Rouse 2007; Smeeding and Phillips 2002). Earnings levels became uniformly lower over the 1970s and the 1980s, at least for male workers. Moreover, failure to obtain a college degree or dropping out of high school dramatically decreases the probability of earning a middle-class wage. For many less-educated individuals, unemployment 
has become a substantial problem, with their unemployment rates significantly higher than those of more educated people. This is especially true for disadvantaged minorities. As with unemployment, wage levels have become more correlated with education level. Shifts in the labor market toward higher-skilled jobs have eroded wages for many with the least education, leading to growing income inequality. Within low-skilled jobs, mobility is also reduced, lowering the possibilities of advancement on the job. Further, jobs overall have also become less stable over time. This created greater uncertainties about young adults' ability and willingness to take on adult responsibilities, and about their long-term socioeconomic characteristics (Duncan, Boisjoly and Smeeding 1996; Hill and Holzer 2006; Oppenheimer 1988). Even when social transfers are taken into account, a significant proportion of young people remain unable to support themselves, and much less a family, before their mid- to late twenties (Smeeding and Phillips 2002).

These outcomes may also contribute to delays in other markers of the transition to adulthood, such as completing education, establishing independent living arrangements, marrying and having children. Certainly, the employment and earning changes of the past four decades have affected the transition to adulthood in ways that vary sharply by gender and education. Education expansion has been more substantial among women, who started from a lower level and managed to catch up with men in getting college degrees and enrolling in graduate studies. The same is true for the labor force participation rate, given that its increase for females has been much more pronounced. If young males with a low level of education take longer now than they did in the mid-1970s to become self-sufficient and to earn enough to support a family by working steadily in a job with good wages and benefits, young women are more likely to attain self-sufficiency now than they were in the mid-1970s (Danziger and Ratner 2010).

The changing economic situation of young men and women has potentially important implications for the second phase of adult transitions, union formation and parenthood. Career opportunities and earnings, in fact, affect decisions about marriage and parenthood differently by gender. Among men, steady employment and earnings are positively associated with marriage and childbearing (Becker 1981; Blossfeld and Drobnič 2001; Blossfeld et al. 2005; Gibson-Davis 2009; Gibson-Davis, Edin and McLanahan 2005). For women, the picture is more complex. The new home economics (Becker 1965; Mincer 1962) hypothesis is that women's economic 
independence is the main reason behind delayed marriage and motherhood in industrialized countries. This independence effect is driven by better education and career opportunities, with consequent higher wages, which enable women to forgo marriage. Gains from marriage and role specialization within marriage dissipate with women's growing investments in human capital and careers. The higher their level of education and the better their job opportunities, the more likely women are to postpone or even avoid marriage and motherhood. An alternative hypothesis, with different implications, is that women's earnings contribute to a couple's higher standard of living, which encourages marriage (income effect). Which scenario dominates is not clear yet and appears to be dependent on other factors such as local and country context, birth cohort, and educational attainment (Harknett and Kuperberg 2009; Sweeney 2002).

There are several reasons behind these changes in labor market outcomes and economic self-sufficiency among young adults. One important factor explaining the delay in the achievement of financial independence is the expansion of education that took place in the last 40 years. Today it takes longer to build the human capital necessary to establish economic independence and as a consequence, a growing number of young adults may linger for a long time in a state of semi-autonomy. As a matter of fact, by spending more time in school they are delaying economic independence and temporarily giving up job earnings, but they are improving their capacity to earn good wages in the future (Bell et al. 2007).

Beginning in the 1970s - and until the late 1980s - the U.S. economy began to experience periods of great instability. Some date the end of rapid real earnings growth and the beginning of slower growth in 1973 after the oil embargo that resulted in a deep recession. At the same time there was an acceleration in the growth of earnings inequality, especially among men (Levy and Murnane 1992). For both men and women, increased inequality in earnings was driven by increased wage variation rather than increased variation in hours worked. The supply shifts alone, however, cannot explain the rapid changes in income inequality. Also the demand for skilled workers relative to unskilled ones played an important role.

During the 1970s the large baby boom cohort entered the labor market creating what has been called the Easterlin Effect. Easterlin's argument theorizes cyclical changes in demographic and social behavior as the result of fluctuations in birth rates and cohort size during the postWorld War II period. Large cohort size reduces the economic opportunities of its members and 
reduces income relative to smaller parental generations (Jeon and Shields 2005; Macunovich 2011; Pampel and Peters 1995). "Low relative economic status in turn leads to lower fertility, higher rates of female labor force participation, later marriage, higher divorce and illegitimacy" (Pampel and Peters 1995). There are mixed findings related to Easterlin's theory, some providing support (Jeon and Shields 2005; Macunovich 2011) and some others claiming that the change in relative cohort size was not predictive - or at least powerfully predictive - of changes in labor market outcomes and social behaviors (Pampel 1993). Even considering the Easterlin effect as true and effective, it can explain only in part the worsening of economic conditions of young adult that has been constant over time since the 1970s. The Easterlin effect should have resulted in cycles in economic opportunities and financial independence in the ensuing decades that have not been observed.

In sum, the structure of the U.S. labor market has changed substantially in the last four decades to face global competitive pressure, decline of unionization, and the raise of jobs demanding high human capital. During this period, a decline occurred in tenure and long-term employment relationships, with a subsequent increase in the proportion of workers with shortterm contracts. Despite the sustained growth in employment in the United States until the Recession of 2007-08, there is longstanding concern that the quality of the stock of well-paying jobs in the economy is deteriorating. Stable jobs with high wages have been replaced by service sector jobs, that report high rates of turnovers, low wages and frequently by part-time employment. Employers need to rely more on temporary workers, on subcontractors, and on part-time workers, because they need more flexibility to face greater uncertainty regarding product demand (Farber 2007).

Along with these structural changes, youths' expectations about what it takes to live independently have risen, along with the actual costs of living. The cost of housing, for example, rose in the last decades, especially from 2000 to 2005, before coming to a sudden halt in August 2008 with the severe economic crisis. This process culminated and stopped with the economic crisis beginning in August 2008. Furthermore, expenditures on children in dual-parent households (middle income) increased on average by 20 percent from 1960 to 2008) (Lino and Carlson 2009). The main drivers of this growth can be found in housing costs, health care expenditures, childcare and education, transportation costs, and clothing. The higher costs of living and of raising a child contributed to growing attitudes that a full-time job was insufficient 
to live independently and build a new, independent household. Yelowitz (Yelowitz 2007) tried to assess how changes in the cost of housing, transportation, and childcare affect living arrangement decisions, and he found that there is a significant effect of housing and transportation costs in the expected direction: the higher the costs, the lower the percentage of young adults living independently. In particular, the results show that rising real housing costs can explain $15 \%$ of the total change in independent house living arrangements in the U.S. between 1980 and 2000 .

Some researchers, though not dismissing the structural roots associated with the extension of education and changes in the labor market for young adults, contend that the changes in the timing of adult transitions can be partially explained by a shift in cultural norms regarding home-leaving and family formation. In this paper we do not specifically consider the possible effect of normative and cultural changes, but we only take into account the growing interest in the role that families and parental socioeconomic status may play in shaping life course trajectories. The precise mechanisms by which family background and socioeconomic status affect the transition to adulthood and the ability to achieve economic self-sufficiency are largely unknown, but presumably include factors such as role modeling, labor market connections, neighborhood influences and parents' ability to make monetary investments in their children. Moreover, the association between parents' socioeconomic status and young adult outcomes may also reflect the intergenerational transmission of genetic traits such as intelligence or motivation (Guldi, Page and Stevens 2007).

This paper examines three specific research questions related to the changing barriers to gaining financial independence:

1: How has timing of the entry into the labor market and of the achievement of financial independence changed since 1970s?

2: How do the trends differ between younger men and women? Has there been convergence between men and women in employment and financial indepence trajectories over time? 3: How do the changes in the transition to adulthood over time differ by social class and family background? Is the role of parental socio-economic status changing over time? 


\section{Data and Methods}

\subsection{Data}

The NLSY are a series of nationally representative samples of young men and women, designed to gather information at multiple points in time on their labor market activities and other significant life events. In this study, we use the NLS Original Cohorts (NLS hereafter), and both the NLSY79 and NLSY97. The first one began in 1966 for men and 1968 for women, interviewing 5,225 young men and 5,159 young women who were age 14-24 (born between 1941 and 1954). The NLSY79 began in 1979 with the survey of 12,686 young men and women who were age 14-22 (born between 1957 and 1964). These individuals were interviewed annually through 1994 and are currently interviewed biennially. The NLSY97 consists of a nationally representative sample of approximately 9,000 youths who were age 12-16 in December 31, 1996 (born between 1980 and 1984). Round 1 of the survey took place in 1997 and respondents are interviewed annually. All these surveys are implemented to document the transition from school to work and into adulthood.

Substantial differences exist between the data sets, but they all collect essential demographic and socioeconomic information. Hence, we know respondents' educational attainment, employment and earnings, partnership status, living arrangements, and some family background details, such as parents' education level. Exploiting data included in these surveys, we compare individuals making the transition to adulthood in 1973, 1987, and in 2007, respectively. Following this strategy we obtain three samples with an almost identical age range (22-30 in the NLS and in the NLSY79, and 22-28 in NLSY97) but in three very different historical contexts. The NLS includes people born in the last years of World-War II and in the Post-war decade, so they can be considered baby boomers. This was a time of substantial economic growth and prosperity. The NLSY79 cohorts (late Baby Boom) were born in a period in which the U.S. economy was still growing and expanding. However, by the time they reached adolescence and earlier adulthood, many of the forces that contributed to the prolongation of adult transitions were underway. Nonetheless, labor market prospects were still relatively good at the end of the 1980s, after a severe recession earlier in the decade during which wage stagnation started and income inequality rose. The NLSY97 cohorts were raised in a period of varying prosperity and in an era when a two or four-year college education became increasingly essential to enter the middle class. 
1973-Round of NLS, Round 9 of NLSY79, and Round 11 of NLSY97 (the focus of this study) include fewer individuals than their respective first rounds owing to attrition. Moreover, the NLSY79 contains a military sample (individuals born between 1957 and 1961 and serving in the military as of September 30,1978) and a group of oversampled economically disadvantaged whites. We exclude both these groups to make the samples more comparable. After dropping these individuals (1,280 of the military sample and 1,643 economic disadvantaged whites) and those with missing information on essential variables, we are left with 6,888 individuals in the NLS (49.4 percent men and 50.6 percent women), 8,590 individuals in the NLSY79 (48.4 percent men and 51.6 percent women) and 7,418 respondents in the NLSY97 sample (51.4 percent men and 49.6 percent women).

\subsection{Methods}

In order to answer the first research question we start by describing the employment situation of the young adults in the three samples. Secure, full-time employment is defined, according to the conventional definition, as working more than 35 hours per week and more than 40 weeks per year. The structure and main characteristics of the samples are reported in Table 1.

\section{Table 1}

We next compute the percentage of young adults who are able to live independently and support themselves with their own earnings. To define the affordability of living independently, we use the poverty thresholds established by the U.S. Census Bureau ${ }^{2}$ and consider economic selfsufficiency to include those who report an income that is greater than 200 percent of the poverty threshold. ${ }^{3}$ In addition, and still using Census Bureau poverty thresholds, we compute the

\footnotetext{
${ }^{2}$ The Census Bureau updates poverty thresholds each year. Values of the poverty thresholds for the years 1960 2008 for families of different sizes are available on the Census Bureau's website, and they differ by age (distinguishing between families with members under and over age 65). Thresholds are the same for all mainland states, regardless of regional differences in the cost of living, and are updated annually for price changes using the Consumer Price Index for All Urban Consumers (CPI-U).

${ }^{3}$ All the analyses presented in Sections 4 and 5 have been repeated using two alternative definitions of economic self-sufficiency. We used the simple poverty line (and not two times the poverty line) as a threshold, and a withinsample threshold, specified as the average income of respondents in 1973, 1987 and 2007, respectively. Results with alternative definitions of economic independence are similar to those presented here.
} 
percentage of individuals who can support a family of three with their earnings (still considering as able to support a family those earning more than 200 percent of the poverty threshold for that family size). Poverty thresholds for years and family units considered in the analysis are reported in Table $2 .{ }^{4}$ All the analyses described above are produced separately for men and women in order to address the first part of the second research question, i.e. how the trends in the transition to economic self-sufficiency differ by gender.

\section{Table 2}

The concept of economic self-sufficiency can be defined in several ways, such as being able to live in a separate household, without any family members and without any financial support from the family of origin. It can also be defined as the ability to establish a partnership and have a child. In addition, the source of economic independence is also relevant. It can be earnings from work, welfare and social transfers in addition to wages, family income, or even loans. Young adults who decide to go to college or graduate studies after that will achieve financial self-sufficiency at an older age than those who do not go to college. However, investing in more education can pay off in the long run and can lead to a more secure job and a higher standard of living. Consequently it is unclear whether economic independence should be evaluated using current income, if any, or the discounted flow of future earnings. Moreover, the current amount of earnings together with expectations about career prospects can influence decisions about standard of living (e.g., affordability of a marriage or of childbearing). Individuals with low incomes in early adulthood may decide not to marry or have children. Others who have higher earnings, or who can expect a substantial wage growth, may feel more secure in deciding to

\footnotetext{
${ }^{4}$ Our measure of financial self-sufficiency is only based on wages and self-employment income, and does not reflect family support, taxes, or welfare transfers. However, reforms to the cash assistance program in 1996 substantially altered access to cash assistance. The 1996 Personal Responsibility and Work Opportunity Reconciliation Act (PRWORA) replaced Aid to Families with Dependent Children (AFDC) program with a more flexible block grant, Temporary Assistance for Needy Families (TANF), attached work mandates and time limits to receipt of welfare. It is impossible to accurately measure its impact with our data (and it is not feasible for the NLS), which can cause some bias in our estimates. However, we computed the total amount of welfare transfers received by respondents in NLSY79 and NLSY97 samples. Hence, we have information about AFDC or TANF, food stamps benefits, unemployment insurance, and Supplemental Security Income in 1986 and 2006. Exploiting this important information, we can add welfare transfers to wages and perform the same kind of analysis implemented using labor earnings. Results including welfare transfers are used as robustness checks, but the main trend and the differences between 1987 and 2007 do not differ substantially from the analyses without welfare transfers.
} 
having a greater number of children. In this case it is hard to classify individuals as economically independent and to establish which one of the two conditions implies greater economic selfsufficiency.

Furthermore, the meaning of self-sufficiency may have changed from 1970s to 2007. Both expectations about what it takes to live independently and the actual costs of living have changed. The housing market conditions and child care services and costs have undergone considerable transformations, as has the welfare system. All these aspects contribute to shaping individuals' attitudes and beliefs about their prospects and strategies to achieve economic independence. Ideally, to answer our research questions, it would be necessary to define economic independence taking into account all the issues discussed above. Our measure should adapt to changes in the costs of living and also to people's expectations. Likewise, it would be necessary to follow people over time in their transition to adulthood, to focus on life course trajectories and to investigate how investments in higher education may delay the achievement of economic independence but also improve the subsequent standard of living. However, the approach we take here is somewhat limited by the nature of the data. We use panel data in a cross-sectional way. We cannot exploit the longitudinal data to follow young adults over time, given that there are only two waves of NLSY97 after Round 11, the one investigated here. This also means that our measure of economic independence is built on current income, rather than a life course approach. However, by just using the NLSY79 and NLS, we would lose ability to compare the current situation with that in the 1980s and 1970s. Consequently, even though our approach is incomplete and partial, it will shed light on the evolution of young adults' characteristics in the United States in the last 40 years and establish the basis for future research when new waves of NLSY97 will be released.

Also, our examination takes account of the importance of social class variations over time by computing the proportion economically independent and/or able to support a family by parents' education level. Parents' education level ${ }^{5}$ is based on three different categories: we divided the distribution of parents' education into terciles, in order to take into account the fact that education expanded over time - not only for respondents, but for parents as well. As a matter of

\footnotetext{
${ }^{5}$ We used the highest level of education between that of the father and that of the mother.
} 
fact, the threshold dividing the first and the second terciles is "10 years of education" in 1973, "11 years of education" in 1987, and "12 years of education" in 2007. Also the threshold dividing the second and the third terciles has changed over time, "12 years of education" in 1973 and 1987, and "14 years of education" in 2007.

Finally, we implement an event history analysis - through some complementary logistic regression models with random effects for individuals (Lancaster 1979; Nickell 1979) - to explore the possibility of a convergence in life course trajectories among men and women, and to investigate the association between the parental social class and the timing of economic selfsufficiency. We merge the three data sets and we include some socio-demographic variables, such as age (as a time-varying covariate) and race, and then we start including other explanatory variables step by step in order to answer our research questions. First we include time dummies to see how the timing of economic independence differs across cohorts, and a gender dummy to detect the distance between men and women. Secondly, we include some interaction terms between the gender dummy and the time dummies to test the hypothesis that there is some convergence over time in the life course trajectories of males and females. Third, we incorporate the covariates referring to family background - parents' educational attainment and whether the respondent was living with both biological parents at age 14 - to shed light on the environment in which the respondent grew up, which may influence the transition to economic independence. Many studies show the effects of parental education, occupation, number of siblings, family income, and other characteristics of family background on the timing of school completion, labor force entry, marriage, and parenthood, and on their sequencing (Duncan, Featherman and Duncan 1972; Hogan and Astone 1986; Marini 1978; Marini 1984). Relatively disadvantaged family circumstances or relatively low levels of resources have been linked to early exit from school, early marriage and parenthood. Having relatively less educated parents, growing up in a household with neither natural parent or with a stepparent, and having more siblings are associated with lower per capita income, which can deter marriage. The impact of family background on the timing of home-leaving is less clear cut. Last but not least, we do interact parental education level with time dummies and also with gender to investigate whether and how the role of family social class has changed in the last four decades, and if it has a different role for men and women. 
The results do not establish causal relationships or uncover exact determinants of economic independence, but the findings can still shed important light on young adults' conditions in the United States.

\section{Trends in financial independence over time}

The first step is to compare the three groups of young adults on employment status and economic independence. The mean age of working full-time is 25.6 in 1973, 25.9 in 1987 and 25 in 2007 (with a standard deviation of 2.5 in 1973, 2.2 in 1987 and 1.4 in 2007, and median age equal to 25 in 1973, 26 in 1987, and 25 in 2007). ${ }^{6}$

Except for the NLS, all NLSY data sets over-sample Hispanics and blacks. Therefore, if the data are not adjusted, the greater number of black and Hispanic respondents would skew population averages toward black and Hispanic averages. For this reason, we adjusted the data using population weights when computing the proportion of those who are employed "full-time" and economically self-sufficient.

Figure 1 reports results for men and women relative to the trends in employment status and economic independence, over time and by age. As expected, the percentage of men working full-time increases with age for all the three groups. However, the percentage of males who have a full-time job is highest in 1973, decreases in 1987, and it is lowest in 2007. Moreover the differences sharpen with age, except for ages 25 and 26, for which we observe very similar percentages in 1973 and 1987. If in 1973, by age 29-30 almost $90 \%$ of males in the sample are employed full-time, this proportion drops to $79 \%$ in 1987 , and to $65 \%$ in 2007 . This is a very clear signal of the worsening in the situation of young males in the U.S. over time.

\section{Figure 1}

Our measure of income sufficiency shows a similar pattern. In this case, however, the difference is apparent even at very young ages and does not decrease with age. Interestingly, in all years - 1973, 1987 and 2007 - the percentage of individuals able to live independently or afford to support a family is lower or at most equal than the percentage working full-time. This

\footnotetext{
${ }^{6}$ Note that the age range is wider in 1973 and 1987 (22-30) than in 2007 (22-28).
} 
suggests that even with a relatively stable job, some young men are unable to earn enough to start their independent households. The distance between these two figures (percentage working full-time and percentage economically self-sufficient) is greatest for NLSY97 respondents. Hence financial independence is lowest in 2007, and this is certainly true at individual level. It is worth mentioning that this might not be the case at household level, given that men in the later cohorts who are in a partnership have combined incomes with working women, or women are completely supporting their spouses. The last graph in Figure 1 referred to young men shows the proportion of respondents able to support a family of 3 people with their earnings. We observe exactly the same pattern as for economic independence, possibly with even larger differences in the three groups.

In contrast to deteriorating economic circumstances over time for men, women's economic position does not erode (bottom part of Figure 1). Nor do we observe the same strong gradient by age in the percentage of women working full-time. An increase with age is still evident for women in 1987 and in 2007, although in the older age groups percentages are very similar, suggesting that there may be an upper limit for the share working full-time (approximately 50-55 percent). Interestingly, if percentages working full-time are very similar in 1987 and 2007, they are much lower in 1973. This shows the considerable increase in educational attainment and, certainly, in female labor force participation rates. It can also depend on a rise in the labor force participation of women with children or on the decline in fertility, or both.

As for economic independence, however, when we look at 1987 and 2007 the results do not show significant differences with respect to men, except for the fact that distance between the two samples decreases with age. The proportion of women who report to be financially independent in 1973 lies in between that for the other two data sets until age 24. From age 25 it is even lower than in 2007, showing once again the improvements of women in the labor market. The pictures describe the progress of women in the 1970s, until the late 1980s, but then show an adjustment that bring them closer to the trend we observed for men. The share of economically independent women is clearly much lower than for men, ranging between 33 percent and 50 percent in 1987, and between 18 percent and 39 percent in 2007. The shares do, however, increase with age and are higher in 1987 than in 2007 at all ages. 
There is a good possibility that education plays a role postponing full-time work. The level of education increased over time, and both men and women in 2007 were enrolled in school longer than their counterparts 20 or 40 years earlier. Being a full-time student normally prevents one from being a full-time worker and from being able to earn enough to be independent. On the other hand, being more educated increases the likelihood of finding a secure job and earning a good wage. We replicated the analyses shown in Figure 1 while excluding those who were still in school in all samples to ensure that the different proportions of students did not bias the results. Results from these analyses do not differ from those shown above.

The next step is to look at how the proportion of young men and women who achieved financial independence differs by level of parents' education. Results are reported in Figure $2^{7}$. Among men we observe an increase with age in the proportion of those self-sufficient, and a monotonic decrease over time periods. Moreover, there is a gradient by education level: the higher the parents' education level, the less evident is the postponement in achieving economic independence. The distance between the the $1^{\text {st }}, 2^{\text {nd }}$ and $3^{\text {rd }}$ terciles would have been much more pronounced if we were looking at respondent's education attainment (Figure 2.A in the Appendix). However, we can still observe an increase from the $1^{\text {st }}$ to the $2^{\text {nd }}$ tercile. Surprisingly there is not such a big difference between the $2^{\text {nd }}$ and the $3^{\text {rd }}$ terciles, as we expected to find a higher proportion of men who achieved financial independence among those with parents in the third tercile and it is not the case. One explanation can be that in the past the real difference was between those with no education or just with primary education and those who attended high school. An high school diploma most likely was enough for parents of respondents interviewed in 1973 and in 1987 to find a good job, earn good wages and so to assure their children a favorable family background and environment where to grow up. If this is true in the past, not necessarily it is accurate to describe the picture in 2007 . However, the threshold between the $1^{\text {st }}$ and the $2^{\text {nd }}$ terciles in 2007 is " 12 years of education", meaning that the difference between the $1^{\text {st }}$ and the $2^{\text {nd }}$ terciles is between those with college educated parents and those with parents who did not attend college.

\section{Figure 2}

\footnotetext{
${ }^{7} \mathrm{We}$ also reproduce the analyses using the number of years from the end of education instead of age. This gives information about the time young adult could spend in the labor market to build up enough income to become economic self-sufficient. Results do not show significant differences (See Appendix).
} 
In this Figure we also show the graphs related to the ability of supporting a family of three persons with wages. The proportion among men is clearly lower, for all periods and for all age groups. Again the percentages increase with age and decrease over time. In this case the distance between the different terciles is more visible, and the gradient of the delay decreases when parents' education increases.

If we look at the two corresponding graphs for women the picture is much more blurred. The proportion of women who achieved economic self-sufficiency increased by age only in 2007, independently on parents' level of education, and in 1987 for women whose parents are in the $3^{\text {rd }}$ tercile of the distribution. Possibly, these graphs show how women are becoming more similar over time in terms of employment and financial independence. On the other hand, if among men we observed a decrease over time in the proportion economically self-sufficient, among women there is an increase from 1973 to 1987, and then just a small decrease in 2007. Moreover, we notice an improvement by parents' level of education, especially from the $1^{\text {st }}$ to the $2^{\text {nd }}$ tercile. The increase by parents' education is slightly less marked in 2007, meaning that probably trends in female labor force participation are becoming less dependent on family background and parents' education. Finally, investigating the ability of women to support a family, we find a striking low proportion that is able to do that among those whose parents are in the $1^{\text {st }}$ tercile of the distribution. In addition, the upward trend in the ability to support a family by parents' education is more evident than that for financial independence itself. The Figures presented above showed clear signals of delay and postponement in the achievement of economic self-sufficiency, even with different degrees of intensity and strength. Delay is more pronounced among men, and it is greater among those whose parents are low educated. Generally speaking, however, if the downward trend is so widespread and apparent, it is extremely important to investigate more deeply the mechanisms behind it. This can be helpful to reduce the postponement by proposing labor market strategies that support young adults to become self-sufficient at an earlier stage. We return to this question in the conclusion of the paper. 


\section{Convergence between genders and the role of parental social class in the timing of economic self-sufficiency?}

As described in section 3.2, we implement an event history analysis - through some complementary logistic regression models - in order to understand which factors are associated with the timing of economic independence (our response variable takes the value of 1 if the respondent is able to support him- or herself, and 0 otherwise). To do that we use our data longitudinally, and build the event history for economic independence to study when respondents became self-sufficient for the first time. Some of them have never achieved independence, and are therefore censored. We describe the results only in qualitative terms, reporting the results of the regression analysis in the appendix (see Table 1A).

As expected age and race are important predictors of self-sufficiency. As a matter of fact being older increases the "risk" of achieving self-sufficiency, while this risk is lower for "nonwhite" respondents. The analyses confirm what we reported in Figure 1, and so that the probability of achieving financial independence is significantly lower for women, and it is also lower in 2007 and 1987 than in 1973 showing the delay of this event over time. But what we are interested in is the possibility of a convergence over time in men and women life course trajectories, and the results reveal that the difference in the timing of economic independence across gender is becoming smaller over time. This is probably due to a strong delay among men and some progress among women, who increase their participation in the labor force.

When we look at the role of family background we find that having parents with high education slightly increases the probability of achieving independence. This means that growing up in an "advantaged" family may have some beneficial effects in terms of economic independence during the transition to adulthood. However the positive role of parents' socio-economic status seems to change over time, being strong and evident in 1987 but not in 1973 and in 2007. Also, the association between parental socioeconomic status and the "risk" of becoming self-sufficient is different between men and women. The beneficial effect that we may observe is stronger for women, suggesting that being from an advantaged family makes it easier to achieve economic independence for a woman than for a man - who is probably better off in terms of employment and earnings independently on the conditions of the family of origin.

A potential limitation should be noted. We do not have information on other key explanatory variables that could potentially shed light on why it is so difficult to achieve 
economic independence and why it became more difficult in the last four decades (e.g., family income, if respondents own the house they live in, etc.).

\section{Discussion and Conclusions}

The transition to adulthood has changed considerably between the 1970s and late 2000s in the United States. It is much more difficult for young adults to achieve economic independence in 2007 than it was 35 years before. A sizable difference exists between 1973, 1987 and 2007 in the percentages of young people able to live independently or to support a family of three people with their own earnings. The picture is to some extent different for men and women. Among young men, the differences grow with age, suggesting that postponement of economic independence is considerable and that over a six-year time span we do not observe any catch up. Among women, we observe an increase over time in the proportion working full-time, due mainly to a substantial expansion of education and an increase in the female labor force participation. Nonetheless there are signs of convergence over time in the situation of men and women concerning the achievement of economic self-sufficiency.

While the postponement of economic independence over the past four decades is clear, the potential implications of the delay for family formation have not been examined directly in this paper. Men's lower proportion working full-time and their later economic self-sufficiency may have a "negative" impact on the timing of marriage (or cohabitation) and parenthood, transferring the delay also on these events (Blossfeld and Drobnič 2001; Blossfeld et al. 2005; Gibson-Davis 2009). The positive results obtained by women do not necessarily counterbalance the effects of men's delay of economic self-sufficiency in family formation (Harknett and Kuperberg 2009; Sweeney 2002). As a matter of fact, an increase in the proportion of women working full-time and able to support themselves may not translate into incentives for marriage and motherhood - as it might happen for men. It certainly depends on which one between the independence and the income effect prevails, not to mention the role of institutions and welfare state.

Education surely plays an important role in achieving economic independence, and the higher the educational attainment, the less likely it is that an individual will live in poverty. Staying in school for a longer time, however, is one possible reason for the delayed entry into the labor force. Hence, if education plays a role because it expanded and more people spend more 
years in school starting later the transition to adulthood, then it is easier to recuperate for those with a college degree.

In the second part of the analysis we have also investigated the role of family background, how it influences the transition to economic independence, how its role has changed over time, and its different impact on men and women. We argue that it is essential to take socioeconomic background into account when trying to interpret the delay in the achievement of financial independence, on top of possible structural changes and possible normative shifts. We found that it has a positive, even if rather small, association with the probability of becoming self-sufficient, and that this association is stronger in 1987 than in 1973 or 2007, and it is stronger among women than among men.

The debate about which one between structural changes in the U.S. economy and labor market, and normative shifts concerning youth's attitudes is still open, and it should be an important topic for future research. In all likelihood these forces are both in place and shape young adults' lives and choices. Their expectations, of course, are not completely independent of the awareness of tougher labor market conditions. At the same time, it is possible that many couples retain preferences in the ideal situation for earlier family formation if economic conditions permitted. However, the early patterns of family formation characteristic of the postwar period were probably not sustainable in an era of a slower growing economic and an increasing demand for higher skills in the labor market. So we suspect that norms have changed, but we also consider it likely that the normative change reflects the new realities facing young adults from the conditions that their parents experienced in the 1980s and their grandparents in the 1960 s.

One of the advances of many developed societies is that they developed mechanisms that allow young adults to do "other things" rather than starting work or a family relatively early. Education is clearly one example of this, which is in part financed by transfers (private and government), loans, and high returns to education. One possible question is whether the young adults who are in higher education today would rather be on a career track as their parents were in their early to mid-20s. In this perspective, the delay could be seen as a response to the opportunities offered to them. To better understand what is happening, future works should look directly at people's attitudes towards employment and what it takes to be self-sufficient, and also should investigate 
the effect of policies aimed at changing the structure of the labor market. Also we need to focus our attention on the possible implications of the delay for the formation of the family, and on how changes in the timing of the first steps in the transition to adulthood may affect timing of other events - i.e. forming a co-residential union and having a child - later in life. But that is the topic of a future paper. 


\section{Tables and Figures}

Table 1. NLS (1973), NLSY79 (1987) and NLSY97 (2007) Sample Characteristics

\begin{tabular}{lccc}
\hline & 1973 & 1987 & 2007 \\
\hline Mean Age & 25.4 & 25.7 & 24.9 \\
\% Female & $50.6 \%$ & $51.6 \%$ & $49.6 \%$ \\
\% Enrolled in school & $10.8 \%$ & $8.5 \%$ & $15.5 \%$ \\
\% in a union & $69.5 \%$ & $50.0 \%$ & $42.5 \%$ \\
\multicolumn{1}{c}{$\%$ Married } & $62.7 \%$ & $42.3 \%$ & $23.6 \%$ \\
\% with at least 1 child & $\mathrm{n} / \mathrm{a}$ & $7.7 \%$ & $18.9 \%$ \\
$\%$ living with parents & $56.3 \%$ & $41.7 \%$ & $34.1 \%$ \\
$\%$ working "full-time" & $21.6 \%$ & $24.4 \%$ & $28.1 \%$ \\
Unemployment rate* & $51.7 \%$ & $54.7 \%$ & $51.8 \%$ \\
Labor Force Participation Rate* & $5.6 * *$ & $7.0 * *$ & $4.6 * *$ \\
& $60.4 * *$ & $65.2 * *$ & $66.2 * *$ \\
$\mathrm{~N}$ & & & 7418 \\
\hline \hline
\end{tabular}

* Source: Bureau of Labor Statistics

**NB: we use information concerning the year preceding the survey 
Table 2. Poverty Thresholds. Source: US Census Bureau

\begin{tabular}{lccc}
\cline { 2 - 4 } & 1972 & 1986 & 2006 \\
\hline 1-person family unit (members age $<65)$ & $\$ 2,168$ & $\$ 5701$ & $\$ 10,488$ \\
3-persons family unit $($ members age $<65)$ & $\$ 3,339$ & $\$ 8,820$ & $\$ 16,227$ \\
\hline NB: we use poverty thresholds of the year preceding the survey, because earnings are \\
referred to that year
\end{tabular}


Figure 1. Share of Men and Women in 1973, 1987 and 2007 Who Were Working Full-Time and Who Had Attained Economic Independence
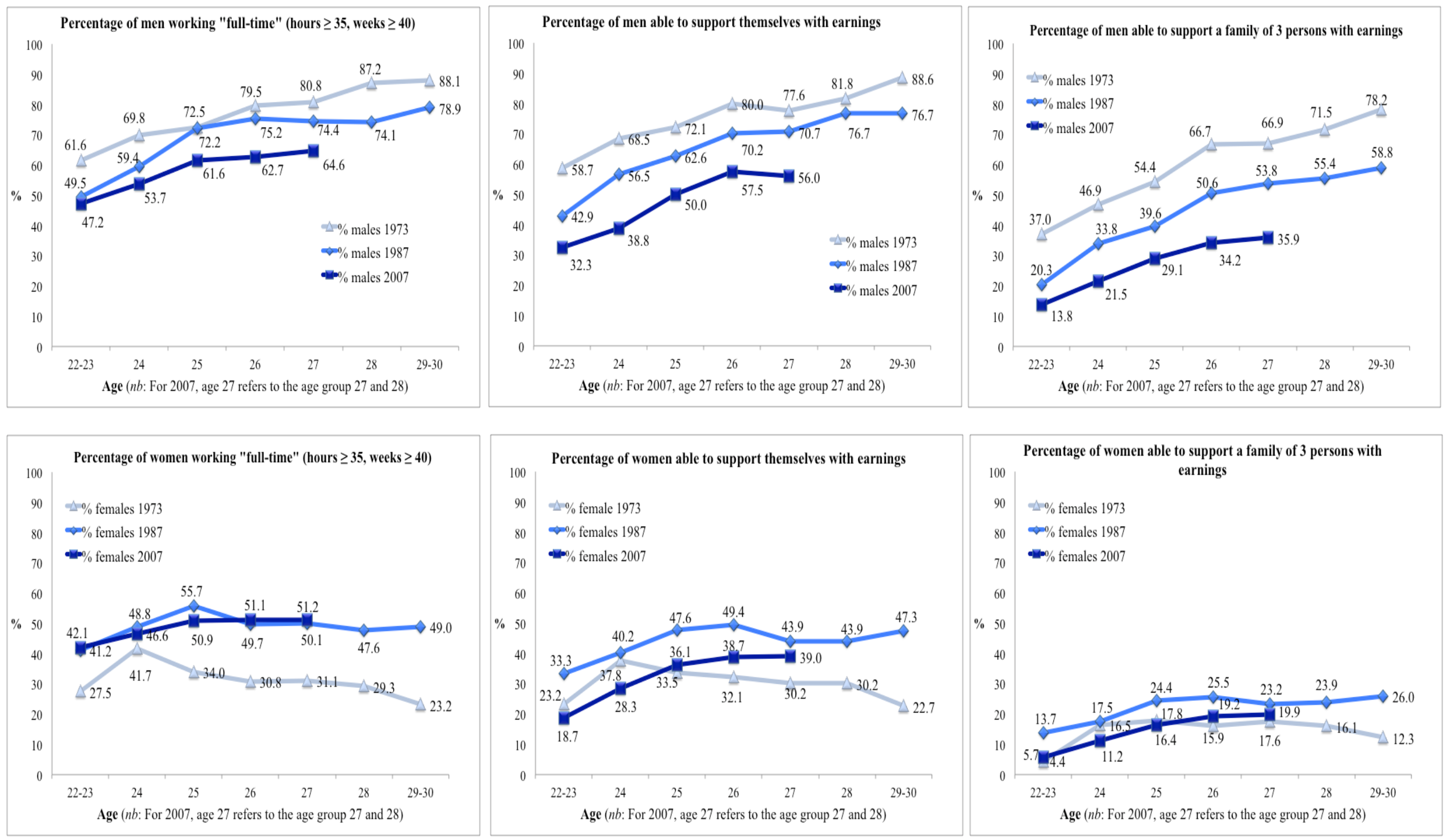
Figure 2. Share of Men and Women in 1973, 1987 and 2007 Who Had Attained Economic Independence, by age and parents' education
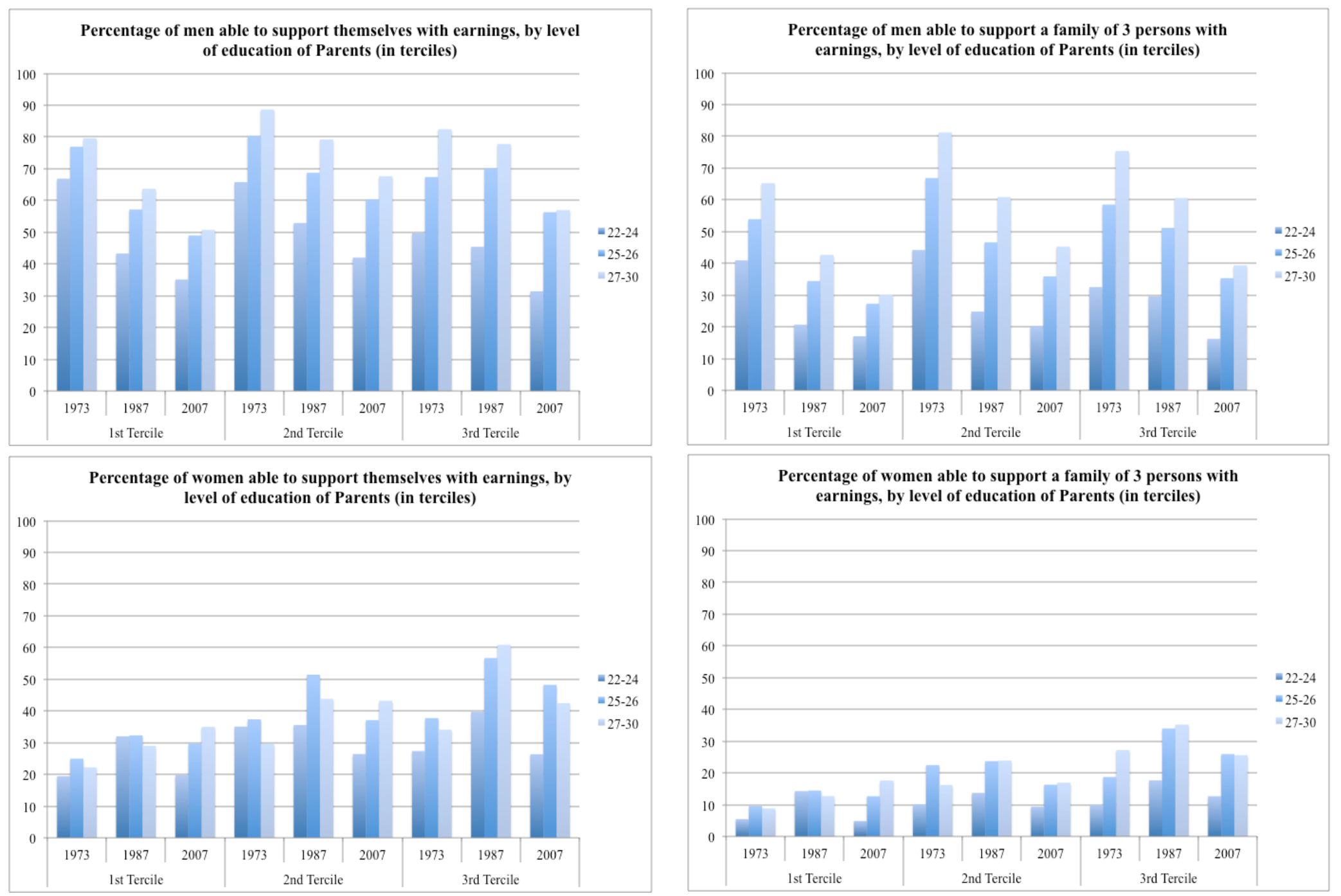


\section{APPENDIX}

Figure 1.A Share of Men and Women in 1973, 1987 and 2007 Who Had Attained Economic Independence, by years from the end of education and parents' education
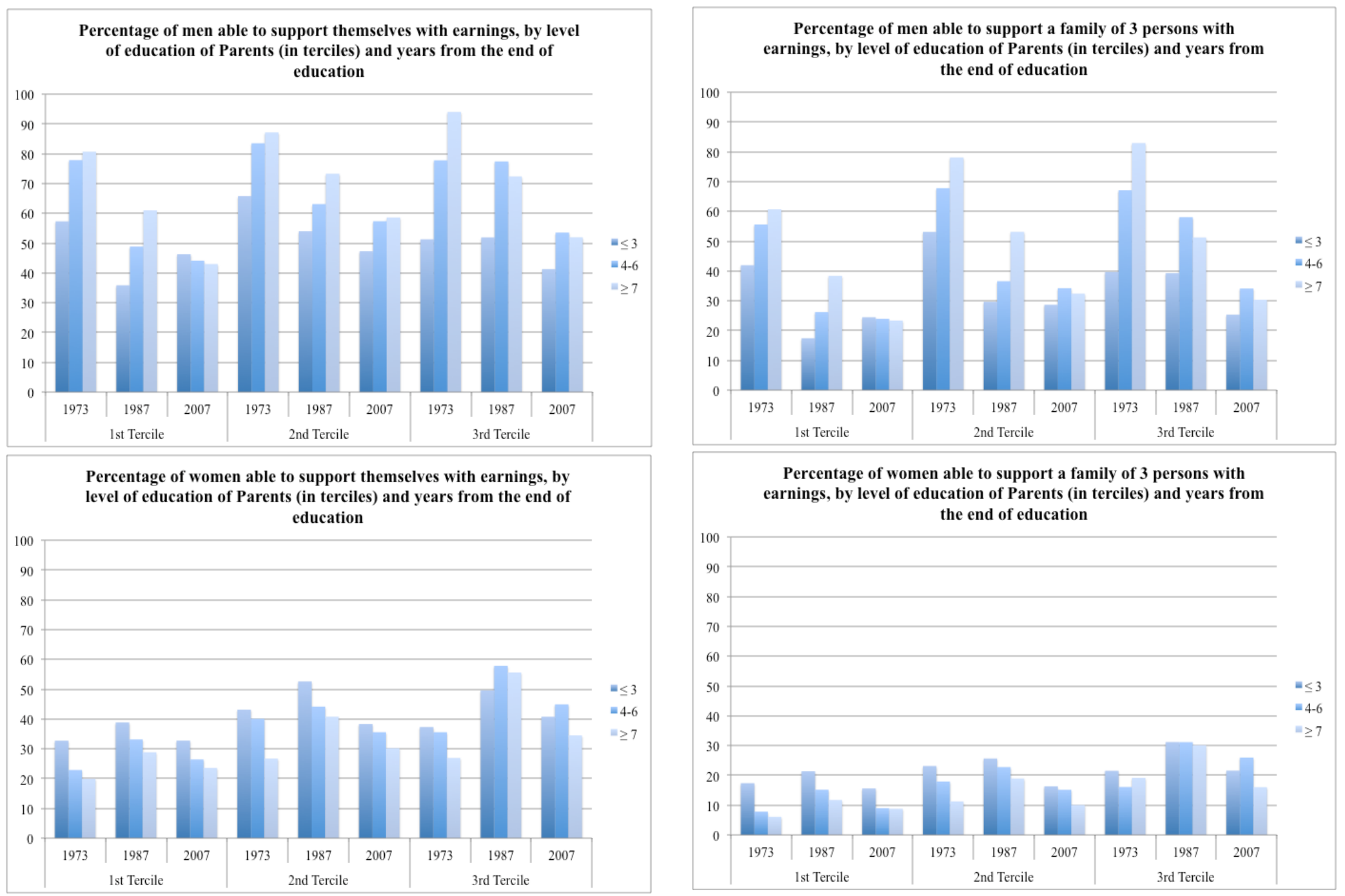
Figure 2.A Share of Men and Women in 1973, 1987 and 2007 Who Had Attained Economic Independence, by age and level of education
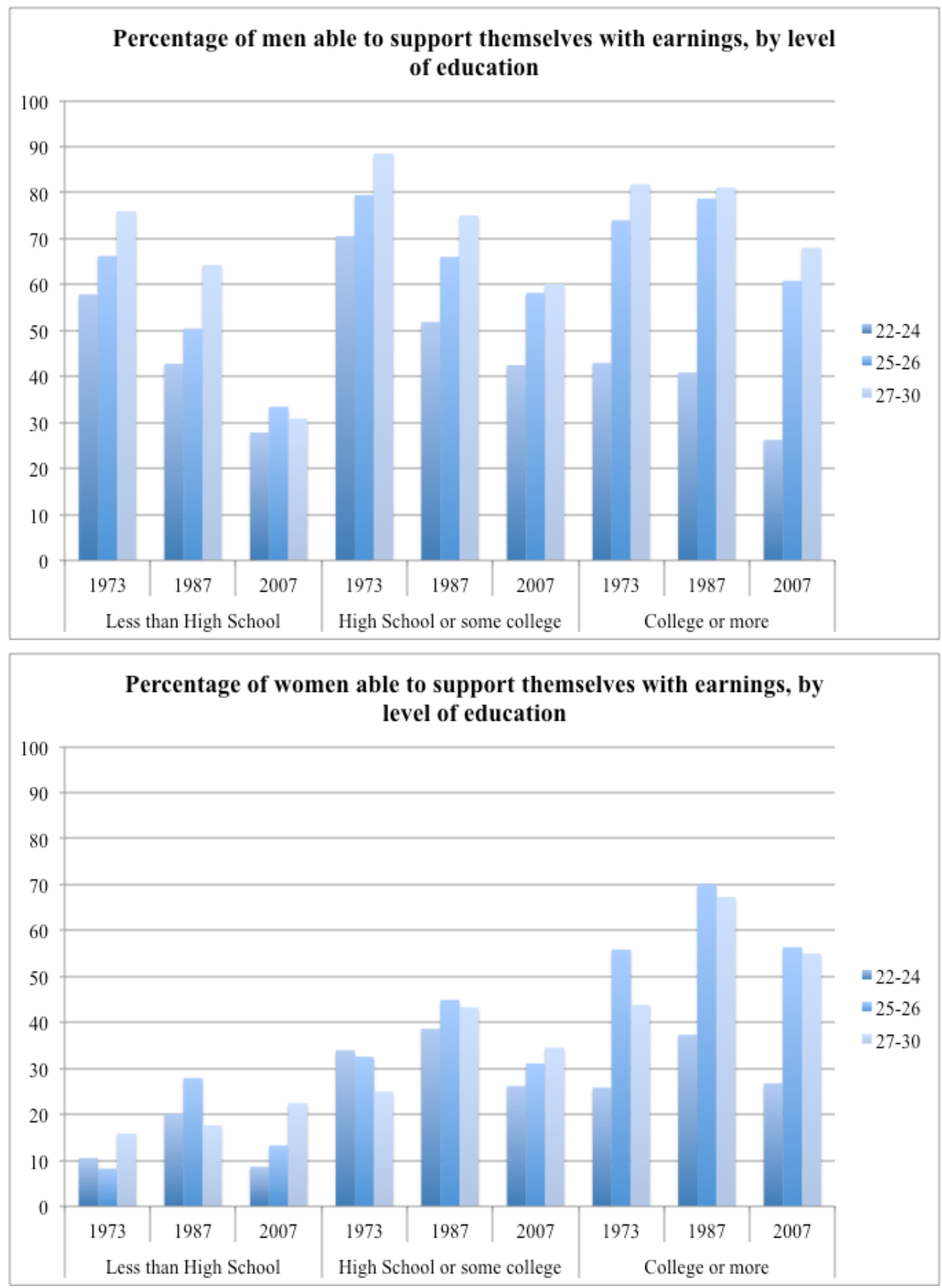
Table $1 A^{8}$.

\begin{tabular}{|c|c|c|c|c|c|}
\hline \multicolumn{6}{|c|}{ Complementary Logistic Regression, $Y=1$ if able to support themselves with earnings, 0 otherwise. } \\
\hline \multicolumn{6}{|c|}{ Number of observations: $22,896.1973: N=6,888.1987: N=8,590.2007: N=7,418$} \\
\hline Odds ratios & (1) & (2) & (3) & (4) & (5) \\
\hline \multirow[t]{2}{*}{ Age } & $1.359 * * *$ & $1.359 * * *$ & $1.373 * * *$ & $1.374 * * *$ & $1.374 * * *$ \\
\hline & [0.005] & {$[0.005]$} & {$[0.006]$} & [0.006] & [0.006] \\
\hline \multirow[t]{2}{*}{ Race: non-white } & $0.633 * * *$ & $0.634 * * *$ & $0.686 * * *$ & $0.694 * * *$ & $0.691 * * *$ \\
\hline & [0.014] & [0.014] & {$[0.017]$} & {$[0.018]$} & {$[0.017]$} \\
\hline \multirow[t]{2}{*}{ Female } & $0.376 * * *$ & $0.166 * * *$ & $0.190 * * *$ & $0.188 * * *$ & $0.147 * * *$ \\
\hline & {$[0.008]$} & {$[0.007]$} & [0.009] & [0.009] & {$[0.008]$} \\
\hline \multirow[t]{2}{*}{$\mathrm{t}: 1987$} & $0.559 * * *$ & $0.359 * * *$ & $0.380 * * *$ & $0.286 * * *$ & $0.291 * * *$ \\
\hline & {$[0.015]$} & {$[0.013]$} & {$[0.015]$} & [0.016] & {$[0.016]$} \\
\hline \multirow[t]{2}{*}{$\mathrm{t}: 2007$} & 0.972 & $0.515 * * *$ & $0.537 * * *$ & $0.503 * * *$ & $0.529 * * *$ \\
\hline & {$[0.026]$} & {$[0.018]$} & {$[0.022]$} & {$[0.029]$} & {$[0.031]$} \\
\hline \multirow[t]{2}{*}{$1987 *$ Female } & & $2.619 * * *$ & $2.264 * * *$ & $2.291 * * *$ & $2.235^{* * *}$ \\
\hline & & {$[0.138]$} & [0.132] & [0.133] & {$[0.130]$} \\
\hline \multirow[t]{2}{*}{$2007 *$ Female } & & $4.005^{* * *}$ & $3.467 * * *$ & $3.492 * * *$ & $3.201 * * *$ \\
\hline & & {$[0.214]$} & {$[0.204]$} & {$[0.205]$} & {$[0.190]$} \\
\hline \multirow[t]{2}{*}{ Live with parents when 14} & & & $1.135 * * *$ & $1.121 * * *$ & $1.122 * * *$ \\
\hline & & & {$[0.030]$} & {$[0.030]$} & {$[0.030]$} \\
\hline \multirow[t]{2}{*}{ Father Education $\geq 12$ yrs } & & & 1.049 & 0.915 & $0.829 * *$ \\
\hline & & & {$[0.027]$} & [0.049] & {$[0.047]$} \\
\hline \multirow[t]{2}{*}{ Mother Education $\geq 12 \mathrm{yrs}$} & & & $1.178 * * *$ & 1.041 & 0.928 \\
\hline & & & [0.032] & [0.056] & {$[0.053]$} \\
\hline \multirow[t]{2}{*}{$1987 *$ Father Education $\geq 12$ yrs } & & & & $1.269 * * *$ & $1.259 * * *$ \\
\hline & & & & {$[0.086]$} & {$[0.085]$} \\
\hline \multirow[t]{2}{*}{$1987 *$ Mother Education $\geq 12 \mathrm{yrs}$} & & & & $1.328 * * *$ & $1.317 * * *$ \\
\hline & & & & {$[0.090]$} & [0.089] \\
\hline \multirow[t]{2}{*}{$2007 *$ Father Education $\geq 12$ yrs } & & & & 1.13 & 1.12 \\
\hline & & & & {$[0.076]$} & {$[0.075]$} \\
\hline \multirow[t]{2}{*}{$2007 *$ Mother Education $\geq 12 \mathrm{yrs}$} & & & & 1.03 & 1.019 \\
\hline & & & & {$[0.071]$} & {$[0.070]$} \\
\hline \multirow[t]{2}{*}{ Female*Father Education } & & & & & $1.259 * * *$ \\
\hline & & & & & {$[0.064]$} \\
\hline \multirow[t]{2}{*}{ Female*Mother Education } & & & & & $1.302 * * *$ \\
\hline & & & & & {$[0.069]$} \\
\hline
\end{tabular}

Standard errors in brackets. P-values: $\mathrm{p} \leq 0.10:^{*}, \mathrm{p} \leq 0.05:^{* *}, \mathrm{p} \leq 0.01:^{* * *}$

${ }^{8}$ As for the analyses presented in Figure 1, we replicated the analyses in Table 3 excluding respondents who are still in education, not to produce biased results due to the expansion of education over time. Results do not show significant changes.

We do not show the results of the models concerning the ability to support a family, given the similarity with those in Table 1A. However, they are available upon request. 


\section{Acknowledgments}

The authors would like to thank Francesco C. Billari for the precious discussions, suggestions and comments that contributed to improve the quality of this work. We are also grateful to HansPeter Kohler for his advices and helpful feedback in earlier drafts of this paper.

\section{References}

Aassve, Arnstein, Simon Burgess, Andrew Chesher, and Carol Propper. 2002. "Transitions from home to marriage of young Americans." Journal of Applied Econometrics 17(1):1-23.

Becker, Gary S. 1965. "A Theory of the Allocation of Time." The Economic Journal 75(299):493-517.

- 1981. A Treatise on the Family: National Bureau of Economic Research, Inc.

Berlin, Gordon, Frank F. Furstenberg, and Mary C. Waters. 2010. "Introducing the Issue." Princeton University.

Billari, Francesco C., and Chris Wilson. 2001. "Convergence towards diversity? Cohort dynamics in the transition to adulthood in contemporary Western Europe." MPIDR Working Papers Max Planck Institute for Demographic Research, Rostock, Germany(WP-2001-039).

Blossfeld, Hans-Peter, and Sonja Drobnič. 2001. Careers of couples in contemporary societies: from male breadwinner to dual-earner families. Oxford: Oxford University Press.

Blossfeld, Hans-Peter, Erik Klijzing, Melinda Mills, and Karin Kurz. 2005. Globalisation, Uncertainty, and Youth in Society. London: Routledge.

Danziger, Sheldon, and David Ratner. 2010. "Labor market outcomes and the transition to adulthood." The Future of children / Center for the Future of Children, the David and Lucile Packard Foundation 20(1):133-58.

Danziger, Sheldon, and Cecilia E. Rouse. 2007. "Introduction." in The Price of Independence: The Economics of Early Adulthood, edited by Danziger and Rouse. New York: Russell Sage Foundation.

Duncan, Greg J., Johanne Boisjoly, and Timothy Smeeding. 1996. "Economic Mobility of Young Workers in the 1970s and 1980s." Demography 33(4):497-509.

Duncan, Otis D., David L. Featherman, and Beverly Duncan (Eds.). 1972. Socioeconomic Background and Achievement. New York: Seminar Press.

Farber, Henry S. 2007. "Is the Company Man an Anachronism? Trends in Long Term Employment in the US, 1973-2005." in The Price of Independence: The Economics of Early Adulthood, edited by Danziger and Rouse. New York: Russell Sage Foundation.

Furstenberg, Frank F. 2010. "On a new schedule: transitions to adulthood and family change." The Future of children / Center for the Future of Children, the David and Lucile Packard Foundation 20(1):67-87.

Gibson-Davis, Christina M. 2009. "Money, Marriage, and Children: Testing the Financial Expectations and Family Formation Theory." Journal of Marriage and Family 71(1):14660.

Gibson-Davis, Christina M., Kathryn Edin, and Sara McLanahan. 2005. "High Hopes but Even Higher Expectations: The Retreat From Marriage Among Low-Income Couples." Journal of Marriage and Family 67(5):1301-12. 
Guldi, Melanie, Marianne E. Page, and Ann H. Stevens. 2007. "Family background and children's transitions to adulthood over time." in The Price of Independence: The Economics of Early Adulthood, edited by Danziger and Rouse. New York: Russell Sage Foundation.

Harknett, Kristen, and Arielle Kuperberg. 2009. "Education, Labor Markets, and the Retreat from Marriage." University of Pennsylvania.

Hill, Carolyn J., and Herry J. Holzer. 2006. "Labor Market Experiences and the Transition to Adulthood." MacArthur Network on Transitions to Adulthood Research Network Working Paper.

Hogan, Dennis P., and Nan Marie Astone. 1986. "The Transition to Adulthood." Annual Review of Sociology 12(ArticleType: research-article / Full publication date: 1986 / Copyright (C) 1986 Annual Reviews):109-30.

Iacovou, Maria. 2001. "Leaving Home in the European Union." ISER working papers Institute for Social and Economic Research.

Jeon, Yongil, and Michael P. Shields. 2005. "The Easterlin hypothesis in the recent experience of higher-income OECD countries: A panel-data approach." Journal of Population Economics 18(1):1-13.

Katz, Lawrence F., and David H. Autor. 1999. "Changes in the wage structure and earnings inequality." Pp. 1463-555: Elsevier.

Lancaster, Tony. 1979. "Econometric Methods for the Duration of Unemployment." Econometrica 47 No.4:939-56.

Levy, Frank, and Richard J. Murnane. 1992. "U.S. Earnings Levels and Earnings Inequality: A Review of Recent Trends and Proposed Explanations." Journal of Economic Literature 30(3):1333-81.

Lino, Mark, and Andrea Carlson. 2009. "Expenditures on Children by Families, 2008." U.S. Department of Agriculture, Center for Nutrition Policy and Promotion. Miscellaneous Publication.

Macunovich, Diane J. 2011. "Re-Visiting the Easterlin Hypothesis: Marriage in the U.S. 19682010." IZA Discussion Papers (5886).

Marini, Margaret Mooney. 1978. "The Transition to Adulthood: Sex Differences in Educational Attainment and Age at Marriage." American Sociological Review 43(4):483-507.

-. 1984. "Age and Sequencing Norms in the Transition to Adulthood." Social Forces 63(1):229-44.

Mincer, Jacob. 1962. "On-the-Job Training: Costs, Returns, and Some Implications." The Journal of Political Economy 70(5):50-79.

Nickell, Stephen. 1979. "Estimating the Probability of Leaving Unemployment." Econometrica 47 No. 5:1249-66.

Oppenheimer, Valerie Kincade. 1988. "A Theory of Marriage Timing." The American Journal of Sociology 94(3):563-91.

Pampel, Fred C. 1993. "Relative Cohort Size and Fertility: The Socio-Political Context of the Easterlin Effect." American Sociological Review 58 No. 4:496-514.

Pampel, Fred C., and Elizabeth H. Peters. 1995. "The Easterlin Effect." Annual Review of Sociology 21(1):163-94.

Settersten, Richard A., Frank F. Furstenberg, and Ruben G. Rumbaut. 2006. "On the frontier of adulthood :theory, research, and public policy." University of Chicago Press. 
Smeeding, Timothy M., and Katherin Ross Phillips. 2002. "Cross-National Differences in Employment and Economic Sufficiency." Annals of the American Academy of Political and Social Science 580:103-33.

Sweeney, Megan M. 2002. "Two Decades of Family Change: The Shifting Economic Foundations of Marriage." American Sociological Review 67(1):132-47.

Yelowitz, Aaron. 2005. "They Just Won't Grow Up." in Time magazine.

—. 2007. "Young adults leaving the nest: The role of the cost of living." in The Price of Independence: The Economics of Early Adulthood, edited by Danziger and Rouse. New York: Russell Sage Foundation. 